\title{
Evidencia del contraste interdental/alveolar en el mapudungun hablado en la costa: un estudio acústico-estadístico ${ }^{1}$
}

Evidence for the interdental/alveolar contrast in the Mapudungun spoken on the coast: an acoustic and statistical study

Mauricio A. Figueroa Candia

Universidad de Concepción Chile

\section{Juan H. Painequeo Paillán \\ Universidad de la Frontera Chile}

\section{Camila Márquez Pradenas \\ Universidad de Concepción \\ Chile}

Gastón F. Salamanca Gutiérrez

Universidad de Concepción

Chile

\section{David A. Bertín González}

Universidad de la Frontera

Chile

ONOMÁZEIN 44 (junio de 2019): 191-216

DOI: 10.7764/onomazein.44.09

ISSN: 0718-5758

\section{(c) $($ i $)$}

Mauricio A. Figueroa Candia: Departamento de Español, Facultad de Humanidades y Arte, Universidad de Concepción, Chile. I Correo electrónico: maufigueroa@udec.cl

Juan H. Painequeo Paillán: Departamento de Lenguas, Literatura y Comunicación, Facultad de Educación, Ciencias Socialesy Humanidades,Universidad delaFrontera,Chile. | Correoelectrónico:juan.painequeo@ufrontera.cl Camila Márquez Pradenas: Programa de Magíster en Lingüística Aplicada, Facultad de Humanidades y Arte, Universidad de Concepción, Chile. I Correo electrónico: cmarquezp@udec.cl

Gastón F. Salamanca Gutiérrez: Departamento de Español, Facultad de Humanidades y Arte, Universidad de Concepción, Chile. | Correo electrónico: gsalaman@udec.cl

David A. Bertín González: Programa de Pedagogía en Inglés, Facultad de Educación, Ciencias Sociales y Humanidades, Universidad de la Frontera, Chile. I Correo electrónico: d.bertin01@ufromail.cl 


\section{Resumen}

El estudio del mapudungun ha mostrado, en general, la existencia de una oposición fonológica entre los segmentos interdentales [!], [n] , [t] y los alveolares [l], [n] y [t] (e. g., Echeverría, 1964; Salas, 1976). Sin embargo, también hay investigaciones en las que se ha puesto en duda tal oposición (e. g., Croese, 1980; Smeets, 1989; Salamanca y Quintrileo, 2009), especialmente en aquellas zonas más susceptibles al contacto con el español. Este estudio tiene como objetivo aportar evidencia para determinar si tal contraste se presenta en el habla de 19 participantes de la zona de Toltén y Mariquina. Para ello, se utilizan las locus equations (Sussman, McCaffrey y Matthews, 1991; Sussman, Hoemeke y Ahmed, 1993) y distintos tipos de regresiones, con el fin de evaluar si existen diferencias estadísticamente significativas entre correlatos acústicos de punto de articulación provenientes de segmentos interdentales y alveolares, para tres modos articulatorios: Iateral, nasal y oclusivo. Además, se explora la relación estadística entre los correlatos acústicos de punto de articulación y las variables cualidad vocálica y sexo. Los resultados de los análisis de 3.437 instancias permiten concluir que existe evidencia para sustentar la hipótesis de un contraste para las consonantes laterales y oclusivas sordas, pero no para las nasales. También se observó un efecto de la vocal que sigue a la consonante, y un efecto de la variable sexo. En suma, los resultados sugieren que el contraste interdental/alveolar para las consonantes nasales se encuentra en proceso de desfonologización, lo que tiene importantes implicancias para la dialectología del mapudungun. Desde una perspectiva metodológica, este estudio releva la pertinencia de la inclusión de técnicas de la fonética acústica y estadística inferencial en el tratamiento de problemas fonético-fonológicos de las lenguas vernáculas chilenas.

Palabras clave: contraste interdental-alveolar; mapudungun; locus equations.

\section{Abstract}

Most previous research on Mapudungun has argued for the existence of a phonemic contrast between interdental-[I], [n], and [t] - and alveolar segments - [I], [n], and [t] (e.g., Echeverría, 1964; Salas, 1976). However, some studies have challenged this hypothesis (e.g., Cro-

1 Estudio desarrollado en el marco del proyecto FONDECYT 11150874, "Estatus fonológico de los segmentos (inter)dentales [n], [I] y [t] y del segmento [j] en las costas de las comunas de Toltén y Mariquina, Chile”, dirigido por el Dr. Juan Héctor Painequeo Paillán, de la Universidad de la Frontera. 
ese, 1980; Smeets, 1989; Salamanca \& Quintrileo, 2009), particularly when analysing data from Mapudungun spoken in areas with a strong Spanish presence. This study aims to provide evidence to determine whether this contrast is present in the speech of 19 participants from Toltén and Mariquina. In order to do this, locus equations were used (Sussman, McCaffrey, \& Matthews, 1991; Sussman, Hoemeke, \& Ahmed, 1993), as well as several types of regression analyses. These techniques aimed to ascertain whether statistically significant differences exist between the acoustic correlates of place of articulation obtained from interdental and alveolar segments, in three manners of articulation: Iateral, nasal and voiceless plosive. The effects on the acoustic data of the variables vowel and sex was also explored. The results of analysing 3437 tokens suggested that there is evidence to support the hypothesis of a phonemic contrast for lateral and plosive consonants, but not for nasals; also, there was a statistically significant effect of vowel and sex. In sum, these results suggest that the phonemic contrast between interdental and alveolar nasals is weakening, which has important implications for Mapudungun dialectology. From a methodological perspective, this study highlights the importance of including techniques from acoustic phonetics and inferential statistics in the study of Chilean vernacular languages.

Keywords: interdental-alveolar contrast; Mapudungun; locus equations. 


\section{Introducción}

El "hablar de la tierra" o mapudungun constituye la lengua del grupo indoamericano más numeroso residente en territorio chileno (Salas, 2006 [1992]), que históricamente se extendió por todo Chile central, aunque actualmente su uso se concentra en zonas de la región metropolitana y fundamentalmente entre la VIII y X regiones. Los datos pertenecientes al censo nacional del año 2012 arrojan, además, que al menos 1.508 .722 personas se reconocen como mapuches, cifra que se aproxima al 85\% de la población indígena total. La incorporación de una buena parte de la población mapuche a la sociedad chilena impuso el castellano a muchos hablantes del mapudungun (Henríquez, 2013), lo que ha tenido un impacto importante en los niveles de vitalidad de la lengua vernácula (e. g., Zuñiga, 2007; Gundermann, Canihuan, Clavería y Faúndez, 2009; Wittig, 2009), hecho demostrado, por ejemplo, en el variable estado de mantenimiento de segmentos focales de la fonología del mapudungun, tales como la denominada sexta vocal /ə/ y, del que se ocupa el presente trabajo, las consonantes interdentales $/ \mathbb{r} /, / \mathrm{n} / \mathrm{y} / \mathrm{t} /$ (véase Mena, 2016).

\subsection{Síntesis del estado del arte}

Sobre el contraste interdental/alveolar, debe señalarse que las investigaciones sobre su estatus fonológico aportan a un tópico conocido y problemático en la literatura². Esto, debido a que los diferentes estudios no siempre coinciden en torno a la existencia del contraste en el sistema fonológico de la lengua mapuche. Al respecto, por ejemplo, Suárez (1959), Echeverría (1964), Salas (1976), Lagos (1981), Salamanca (1997) y Sadowsky, Painequeo, Salamanca y Avelino (2013), entre otros, proponen la existencia de los fonemas interdentales y alveolares y, por tanto, de la vigencia del contraste en zonas como Malleco, Cautín y Alto Bío Bío. Sin embargo, otros estudios como los de Croese (1980) y Smeets (1989) reportan una escasa ocurrencia del contraste para el mapudungun en general, o para algunas zonas geográficas en particular, como en el caso de Salamanca y Quintrileo (2009) en su estudio sobre Tirúa³. En esta misma línea, respecto del habla de la población escolar de Alto Bío Bío, Henríquez reporta la "pérdida de los fonemas (inter)dentales $/ \mathbf{n} /, / \mathbf{1} / \mathrm{y} / \mathrm{t} /[$ [...], los cuales fueron sistemáticamente reemplazados por los fonos alveolares [t], [n] y [l], aunque [...] aún se observan realizaciones residuales

2 Para un estado del arte in extenso, que no será repetido acá, consúltese, por ejemplo, Salamanca, Soto, Painequeo y Jiménez, 2017.

3 Para descripciones completas de los inventarios fonético y fonológico del mapudungún, que permiten evaluar el lugar que tiene el contraste interdental-alveolar desde una perspectiva sistémica, sírvase consultar a Echeverría (1964), Salas (1976, 1978) y Sadowsky y otros (2013). 
de los fonos nasal interdental [n] y lateral interdental [1]" (2013: 195), a lo que se suman las observaciones de Painequeo (2014), quien propone una vigencia del contraste en la zona costera de Budi, pero no en la zona interior; las de Henríquez y Salamanca, en torno a la particular inestabilidad de los fonemas interdentales en Alto Bío Bío (2015: 19); y más recientemente las de Mena (2016), quien, también para Alto Bío Bío, concluye que los fonemas interdentales nasales y laterales presentan un rango de vitalidad relativamente bajo, cercano al 60\%-75\%. Esta discrepancia en el estado de la cuestión releva la importancia de la determinación del estatus fonémico de los segmentos interdentales, en general, y en la zona que nos ocupa en particular (Toltén y Mariquina), con la finalidad de obtener una visión más completa de su eventual vitalidad, y de procesos de cambio vigentes en la lengua.

\subsection{Métodos para la determinación del estatus fonémico de las consonantes interdentales}

Los métodos que hasta aquí se han utilizado para aportar evidencias respecto del contraste interdental versus alveolar en mapudungun han sido el análisis distribucional y estructuralista (e. g., Echeverría, 1964; Salas, 1976; Salamanca, 1997; y Salamanca, Soto, Painequeo y Jiménez, 2017), complementado mediante el conteo de frecuencias de aparición de las variantes, la inspección visual de imágenes capturadas por cámaras de video y la palatografía estática (Salamanca y otros, 2017). En el caso del primer enfoque, Ios autores justifican las oposiciones fonológicas mediante evidencia de pares mínimos y submínimos recogidos del habla de sus participantes. Por ejemplo, Salamanca y otros (2017) proveen los pares submínimos recogidos en la tabla 1 para sustentar su interpretación de contraste fonológico para las consonantes nasales.

\section{TABLA 1}

Pares submínimos para apoyar la hipótesis del contraste entre unidades fonológicas nasales (inter)dentales y alveolares en Alto Bío Bío (Salamanca y otros, 2017). Tabla utilizada con permiso de los autores

\begin{tabular}{|c|c|c|}
\hline CONTEXTO & TRANSCRIPCIÓN & TRADUCCIÓN \\
\hline \multirow{2}{*}{ \#_ } & [na.mun] & pie \\
\hline & [na.' 'tsi] & natre \\
\hline \multirow{2}{*}{$V_{\text {_ }} V$} & [we.'ni] & amigo \\
\hline & [yə.ne.'tfen] & Dios \\
\hline \multirow{2}{*}{$-C$} & ['an.tə] & sol \\
\hline & [kjin.'tun] & buscar \\
\hline \multirow{2}{*}{ —\# } & [wə⿱一兀] & boca \\
\hline & [po.wun] & llegué allá \\
\hline
\end{tabular}


Con respecto al conteo de frecuencias, autores como Salamanca y otros (2017) señalan que, si bien es claro que los segmentos interdentales ocurren en Alto Bío Bío, en muchas de las palabras en las que era previsible su ocurrencia la frecuencia con que se presentan fluctúa de hablante en hablante, y agregan que una aproximación como esta permite recoger información gradual sobre proporciones de aparición —en oposición a una perspectiva binarista de presencia o ausencia completa del contraste-, lo que en consecuencia provee una visión más completa sobre el fenómeno.

La revisión de registros visuales, por su parte, también ha demostrado ser adecuada para evidenciar la presencia de los segmentos en cuestión, como lo ilustra la figura I para variantes interdentales de dos hablantes de Alto Bío Bío, dado que permite interpretar de manera sistemática la presencia o ausencia de la interdentalización (aunque no su grado). Por último, en cuanto a la palatografía, esta técnica permite obtener información visual sobre las características articulatorias de cualquier segmento en el que haya contacto entre articuladores, tanto para el órgano activo como pasivo (Anderson, 2008), lo que permite comprobar los puntos de articulación de consonantes interdentales y alveolares, como ha sido ejemplificado por Salamanca y otros (2017) en las imágenes provistas en la figura 2.

\section{FIGURA 1}

Capturas de video de realizaciones interdentales. En el panel izquierdo se observa a una hablante del sector de Queuco, y en el derecho a una del sector de Biobío. Imágenes tomadas de Salamanca y otros (2017), con permiso de los autores

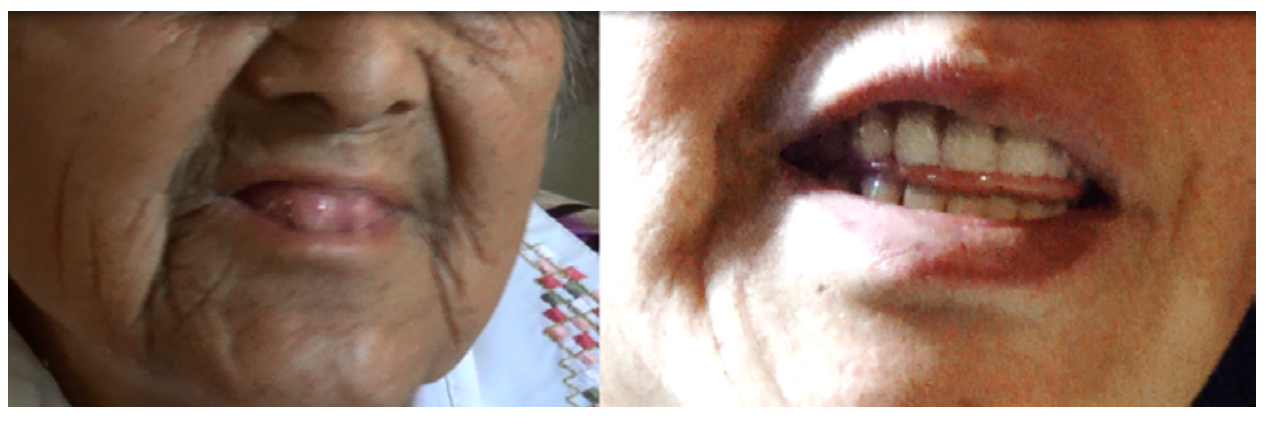

Aunque la reciente incorporación de técnicas como el visionado de imágenes y la palatografía estática ha venido a reforzar los conocimientos que se tienen sobre algunos aspectos del nivel fonético-fonológico de la lengua, todavía resta por incorporar de manera sistemática herramientas contemporáneas de la fonética acústica y de la estadística inferencial para avanzar hacia la resolución de problemas fonético-fonológicos del mapudungún, pero también de las demás lenguas vernáculas chilenas. Si bien existen algunos precedentes de investigación relativamente recientes que adoptan técnicas como las mencionadas (para las vocales, Sadowsky, Painequeo, Salamanca y Avelino, 2013; Fuentes-Grandón y Salamanca, 2016; Soto-Barba, Lara y Salamanca, 2016, para las consonantes), su utilización es la excepción a la norma. 


\section{FIGURA 2}

Imágenes de palatografía estática para consonantes nasales. En el panel izquierdo, se observa un registro para el fono [n], con claro contacto del articulador activo en la zona postdental, y en el derecho, palatografía del fono [n], sin ese contacto. Imágenes tomadas de Salamanca y otros (2017), con permiso de los autores

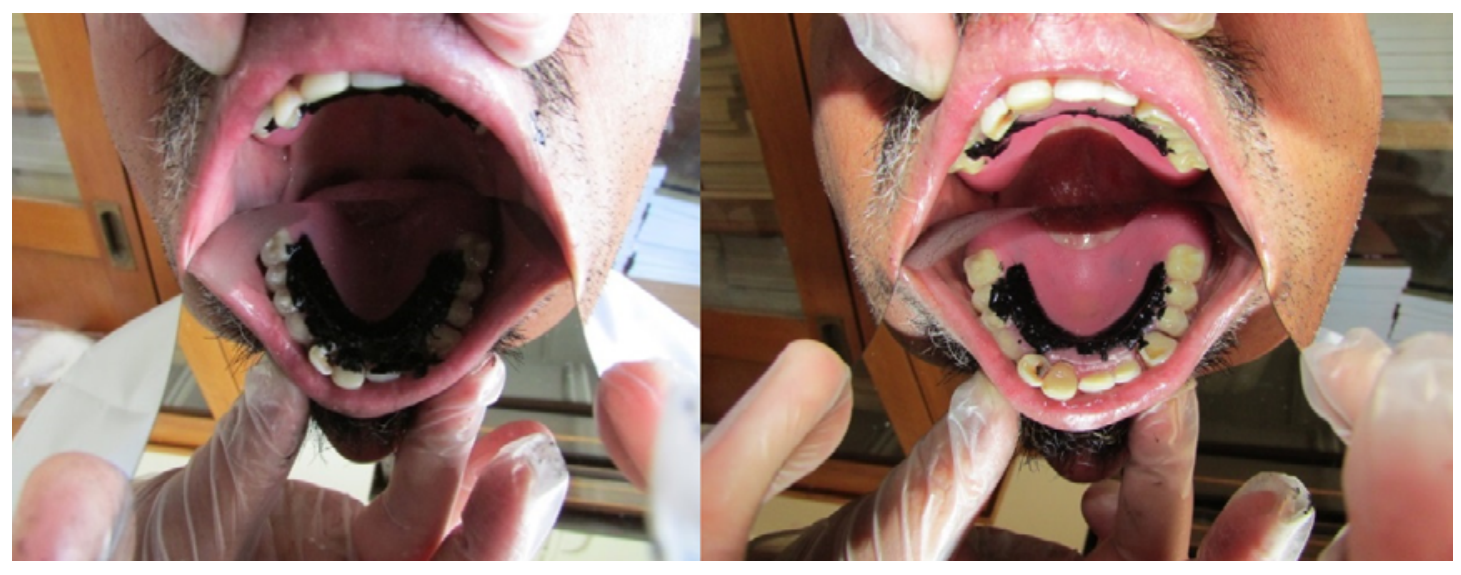

En este trabajo, se propone utilizar correlatos acústicos de punto articulatorio, las locus equations (Sussman y otros, 1991; Sussman y otros, 1993), en conjunto con técnicas de estadística inferencial, para avanzar hacia la determinación del estatus fonológico del contraste interdental/alveolar en tres oposiciones fonológicas del mapudungun hablado en los sectores de Toltén y Mariquina, en particular, para los modos de articulación lateral, nasal y oclusivo áfono. Además, este estudio se plantea como objetivo determinar si existe una relación estadística entre la variable punto de articulación y las variables vocal (que sigue a la consonante) y sexo. Hasta donde se tiene noticia, las técnicas asociadas a las locus equations solo han sido aplicadas en la evaluación de este contraste de manera piloto para un hablante del mapudungún y con un corpus de datos pequeño (véase Fasola, Painequeo, Lee y Perkins, 2015), de manera que todavía resta por determinarse su utilidad en un corpus mayor.

\section{Metodología}

\subsection{Delimitación geográfica y participantes}

Los datos fueron obtenidos en dos macro-localidades: Ia zona costera de Toltén, que considera las comunidades indígenas de Kayulfu, Puralaco, Pu Chilco, y la zona costera de Mariquina, que incluye las comunidades indígenas de Chanchan y Alepúe, pertenecientes a los subsectores V y VII de Croese (1980). Los datos provienen de 19 hablantes nativos del mapudungun, con dominancia en esa lengua (Lambert, 1955), femeninos $(n=5)$ y masculinos $(n=14)$, y con una edad promedio de 64,2 años. 


\subsection{Herramientas de elicitación y estándares técnicos}

La recolección de datos se realizó mediante listas léxicas diseñadas para elicitar pares mínimos y submínimos (Pike, 1971 [1947]) que facultaran el análisis fonológico de algunos aspectos controversiales de la lengua - no solo los reportados acá. Las grabaciones se llevaron a cabo con micrófonos de condensador unidireccionales integrados a grabadoras portátiles TASCAM DR-40, en formato WAV (mono), con una frecuencia de muestreo de $44.100 \mathrm{~Hz}$ y una profundidad de 16 bits. Dado que la toma de datos ocurrió, en la mayoría de los casos, en los mismos domicilios de los participantes, las condiciones de grabación no siempre fueron las óptimas, aunque en general la relación señal-ruido se consideró adecuada $(\bar{x}=36.37 \mathrm{~dB}, \sigma=$ $5.14 \mathrm{~dB}$ ). Para asegurar la calidad de los datos acústicos por extraer, durante los procesos de anotación de las señales se tuvo la precaución de no incluir segmentos en los que el habla de los participantes se solapara con ruidos ambientales o con la de otros hablantes.

\subsection{Segmentación y etiquetado}

La identificación del contraste interdental/alveolar en el corpus se realizó mediante un análisis auditivo. Todas las instancias del contraste interdental/alveolar seguidas de vocal fueron identificadas, segmentadas y etiquetadas en TextGrids de Praat (Boersma y Weenink, 2016), por un fonetista entrenado. La anotación de cada una de las instancias fue revisada luego por segunda y tercera vez, de manera independiente, por parte de dos autores del presente trabajo.

Para la segmentación de las consonantes laterales y nasales, se identificó el inicio y fin de la consonante como el lugar de cambio abrupto de la estructura formántica con respecto a vocales o consonantes adyacentes. En el caso de las variantes de oclusivas sordas, la selección del inicio de la consonante fue identificada como el inicio de la zona de silencio de la constricción articulatoria, mientras que el punto de término fue identificado como el final de la barra de oclusión. Como se indicó más arriba, para todas las instancias de las seis consonantes se identificó y segmentó también la vocal que las sigue, dado que la extracción de los datos acústicos con los que trabajan las locus equations lo requiere; consecuentemente, las consonantes interdentales y alveolares en posición de coda silábica y final de palabra fueron excluidas del análisis4. En la figura 3 pueden apreciarse ejemplos de las características espectrográficas y de la aplicación de los criterios de anotación de las seis consonantes en estudio.

4 La estructura de patrón silábico máximo en mapudungun es CVC. Mientras las consonantes nasales y laterales pueden aparecer en posiciones de ataque y coda silábico, las consonantes oclusivas sordas solo ocurren en el ataque (Echeverría, 1964). 


\section{FIGURA 3}

Formas de onda, espectrogramas, traqueo formántico y anotación de una instancia de cada uno de los 6 fonos en estudio. En el panel superior izquierdo, se observa una lateral interdental; en el superior derecho, una lateral alveolar; en el medio izquierdo, una nasal interdental; en el derecho, una nasal alveolar; en el panel inferior izquierdo, una consonante oclusiva sorda interdental, y en el panel inferior derecho, una oclusiva sorda alveolar
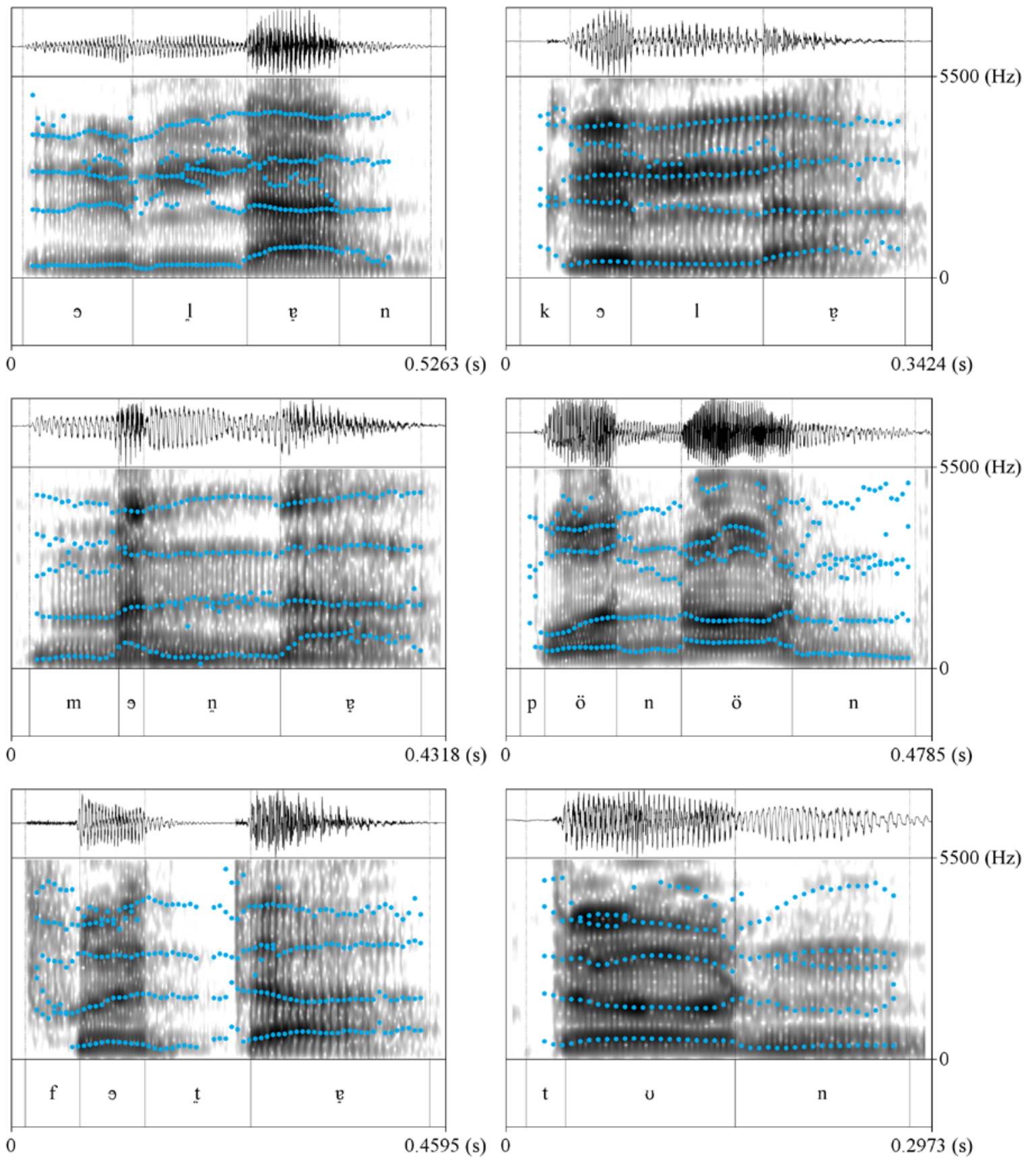


\subsection{Características del corpus obtenido}

El corpus resultante corresponde a 3.437 instancias de variantes interdentales y alveolares, de consonantes nasales, laterales y oclusivas sordas (véase la tabla 2). Como se puede apreciar, el corpus es considerablemente mayor que el del único precedente de investigación directo, en el que se trabajó con 217 instancias (Fasola y otros, 2015).

\section{TABLA 2}

Cantidad de instancias de consonantes interdentales y alveolares para los tres modos de articulación en estudio

\begin{tabular}{lcc|c} 
& LATERALES & NASALES & OCLUSIVAS \\
\hline Interdentales & 477 & 269 & 615 \\
\hline Alveolares & 1054 & 498 & 524 \\
\hline
\end{tabular}

\subsection{Extracción de datos acústicos (locus equations) y normalización}

Para todas las instancias de variantes interdentales y alveolares identificadas, se procedió a extraer valores acústicos para el cálculo de las locus equations, que han demostrado ser buenos correlatos de punto articulatorio para consonantes de varios tipos (ver Iskarous, Fowler y Whalen, 2010; Sussman y otros, 1991; Sussman y otros, 1993; sin embargo, véase también Fowler, 1994). Las locus equations disponen en una relación lineal los valores formánticos de F2 obtenidos en el medio de vocales, con los valores de F2 obtenidos en el límite entre las mismas vocales y las consonantes que las preceden (en adelante "ataque"), para estructuras CV. En el fondo, las locus equations modelan las transiciones formánticas existentes en el tránsito entre consonantes y vocales, descritas originalmente como buenos correlatos perceptuales de punto articulatorio para consonantes oclusivas (Liberman, Delattre y Cooper, 1952; Liberman, Delattre, Cooper y Gerstman, 1954; Liberman, Cooper, Shankweiler y StuddertKennedy, 1967), pero luego extendidas a otros modos articulatorios (Fasola y otros, 2015).

La revisión de los precedentes de investigación reveló que existen dos estrategias para la extracción de valores formánticos para las locus equations: mientras Fowler (1994) y Sussman y otros (1993) los extraen en el punto límite entre la consonante y la vocal, y en el punto medio de la vocal (en adelante, método “A”), Fasola y otros (2015) obtienen los valores del ataque como el promedio de F2 de una porción de 10ms, tomado 5ms luego del límite exacto entre la vocal y la consonante, y como el promedio de F2 de una sección consistente en un 20\% de la duración de la vocal, centrada al medio, o de al menos 1oms de duración, en el caso de que el 20\% de duración fuera menor que 10ms (en adelante, método “B”). Los valores de F2 para cada estructura CV fueron extraídos para los métodos A y B mediante una rutina escrita para 
el programa Praat (Boersma y Weenink, 2016), a partir de objetos formante construidos con valores por defecto, exceptuando el valor formántico máximo de entrada, definido como 5.000 $\mathrm{Hz}$ para hablantes de sexo masculino y $5.500 \mathrm{~Hz}$ para hablantes de sexo femenino (ambos para 5 formantes). En la figura 4, se aprecian gráficos de cajas que comparan los valores formánticos en el ataque y al medio de las vocales, para ambos métodos. Como se puede apreciar, los métodos proveen datos cuyas distribuciones son bastante similares, aunque en el caso de los valores obtenidos en el ataque los datos del método A parecen ser ligeramente superiores que los del método B. Pruebas $t$ de Student — pareadas y de dos colas - realizadas en el programa $R$ (R Core Team, 2017) revelaron que, en efecto, no existen diferencias estadísticamente significativas entre los valores de F2 obtenidos en la zona central de la vocal mediante los métodos $A(\bar{x}=1433.67, \sigma=382.12)$ y método $B(\bar{x}=1433.2, \sigma=374.58), t(3436)=0.527, p=0.599$; $\sin$ embargo sí se observaron diferencias estadísticamente significativas entre los valores de $\mathrm{F} 2$ obtenidos en el ataque para $\mathrm{A}(\bar{x}=1521.34, \sigma=281)$ y $B(\bar{x}=1495.39, \sigma=310.69), t(3436)=10.123, p<$ 0.001, por lo que los valores acústicos de ambos métodos no pueden considerarse como equivalentes. Con la finalidad de evaluar cuál de los dos métodos provee valores más adecuados para el presente estudio, se procedió a observar mediante pruebas de regresión logística la capacidad de las distribuciones de valores de F2 tomados en el ataque por los métodos A y B de predecir la variable punto de articulación. Las pruebas se llevaron a cabo en $R$ mediante el paquete mlogit (Croissant, 2013). Ambos modelos de regresión logística mostraron resultados estadísticamente significativos, esto es, fueron capaces de predecir la variable dependiente significativamente mejor que los modelos nulos correspondientes: para el método $A, \chi_{2}(1)=$ 19.741, $p<0.001$ (Nagelkerke $R^{2}=0.0104$; McFadden $R^{2}=0.0071$ ), y para el método $B, \chi 2(1)=10.166$, $p<0.01$ (Nagelkerke $R^{2}=0.0053$; McFadden $R^{2}=0.0037$ ). A juzgar por la proporción de varianza explicada y el tamaño de efecto del modelo, los valores de F2 del ataque obtenidos mediante el método A son ligeramente mejores prediciendo la variable punto de articulación, de manera que en adelante se utilizarán exclusivamente los datos acústicos extraídos mediante este método. Es importante consignar, sin embargo, que para ambos análisis tanto el porcentaje de varianza explicada como el tamaño de efecto son pequeños.

Dado que es probable que en los datos de F2 exista variación proveniente de las diferencias anatómicas entre los hombres y las mujeres de la muestra (Pisanski y otros, 2014), es de importancia discutir brevemente aquí si corresponde normalizar los formantes vocálicos mediante alguna de las técnicas disponibles para tal fin. Mientras los efectos de las diferencias anatómicas en valores formánticos se encuentran bien descritos en la literatura de vocales (Adank, Smits y Van Hout, 2004), no existen precedentes de investigación en la literatura sobre locus equations en los que se hayan normalizado valores formánticos - ni para aquellos obtenidos en el ataque, ni para los obtenidos al medio de la vocal. En el caso de los datos de F2 del presente estudio, aplicar algunos de los procesos de normalización más típicamente utilizados tiene diversos efectos, según consta en la figura 5, en circunstancias que deberían presentar resultados relativamente parecidos (íd.): mientras un método como la normaliza- 


\section{FIGURA 4}

Valores de F2 para todos los tokens $(n=3.437)$, medidos en el límite entre la consonante de interés y la vocal que la sigue ("Ataque") y en el medio de la vocal ("Medio"), mediante los métodos A (basado en puntos) y B (basado en promedios)

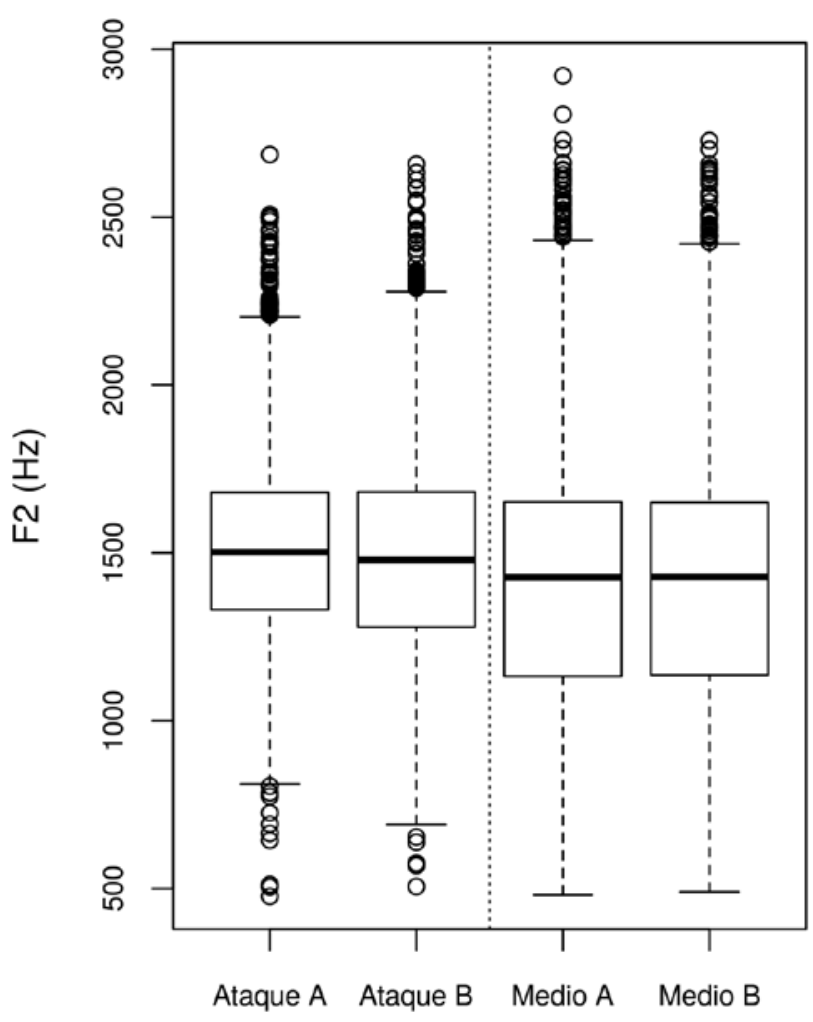

ción vía transformación a valores Z de Lobanov (1971) remueve por completo las diferencias de F2 entre los datos obtenidos en el ataque y en el medio de la vocal, el método Nearey 1 (Nearey, 1977) reduce las diferencias en algún grado, aunque sin removerlas por completo, y Nearey 2 (íd.) acentúa las diferencias entre ambas mediciones. En atención al hecho de que los precedentes de investigación no normalizan los valores de F2, y a los variados efectos que presentan los distintos métodos de normalización en los valores formánticos, en este estudio se ha decidido no normalizar los valores de F2, lo que deberá ser tomado en cuenta en la interpretación de los resultados que se presentarán a continuación, y en su discusión.

\section{Análisis y resultados}

A continuación, se presentarán los análisis estadísticos y sus principales resultados. Para cada modo de articulación, se ofrecerá primero una visión general de los datos, y luego se procederá a entregar detalles sobre regresiones lineales múltiples que fueron utilizadas para 


\section{FIGURA 5}

Valores de F2 medidos en el límite entre la consonante de interés y la vocal que la sigue ("Ataque") y en el medio de la vocal (“Medio"). En el primer panel, se muestran los valores originales; en el segundo, los datos normalizados mediante el método Lobanov (1971); en el tercero, aquellos normalizados mediante el método Nearey 1 (Nearey, 1977); y en el cuarto panel, los valores normalizados mediante Nearey 2 (íd.)
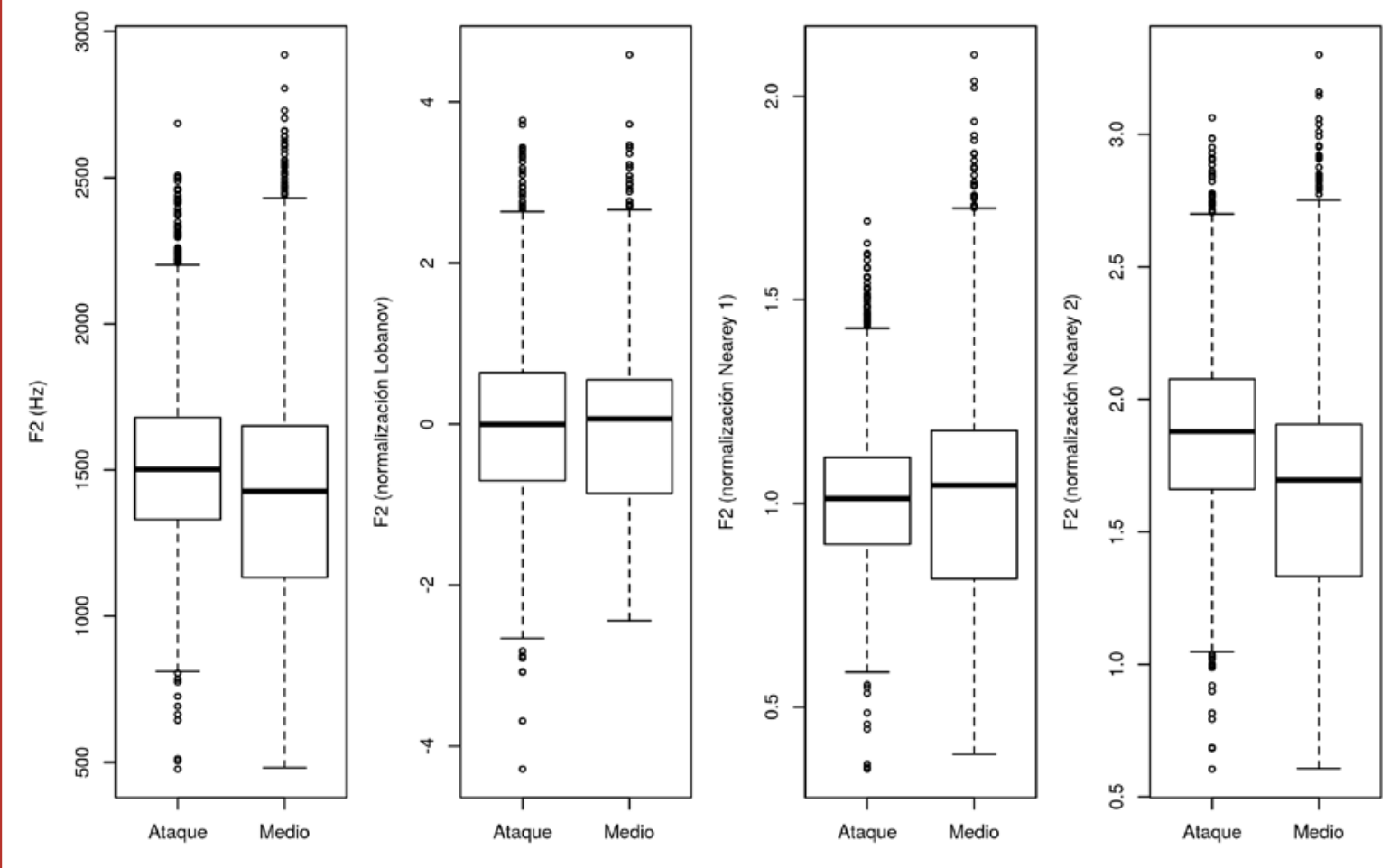

evaluar la capacidad que tienen algunas variables categóricas para predecir valores formánticos. Siguiendo a Fasola y otros (2015), fuera de las visualizaciones de las locus equations, se han realizado análisis estadísticos separados para los valores de F2 obtenidos en el ataque de aquellos obtenidos en el medio de la vocal.

\subsection{Consonantes laterales}

La figura 6 muestra un gráfico de puntos que dispone en una relación lineal los valores de F2 de consonantes laterales obtenidos al medio de la vocal, en el eje horizontal, con aquellos medidos en el ataque, en el eje vertical. La inspección de la figura 6 revela que, efectivamente, para ambos puntos de articulación existe una correlación positiva, tal que, a mayores valores de F2 en la mitad de la vocal, se observan mayores valores de F2 en el ataque. También es posible observar que ambas líneas de regresión lineal ajustadas al gráfico de puntos presentan trayectorias similares, pero que, sin embargo, no se solapan por completo, lo que sugiere 
potenciales diferencias acústicas entre las transiciones de las consonantes laterales interdentales y alveolares.

\section{FIGURA 6}

Gráfico de puntos para los valores de F2 medidos como un promedio al medio de la vocal y para los del ataque, para consonantes laterales interdentales $(n=477)$ y laterales alveolares $(n=1054)$. Para cada punto articulatorio se han ajustado líneas de regresión lineal y sus respectivos intervalos de confianza (95\%)

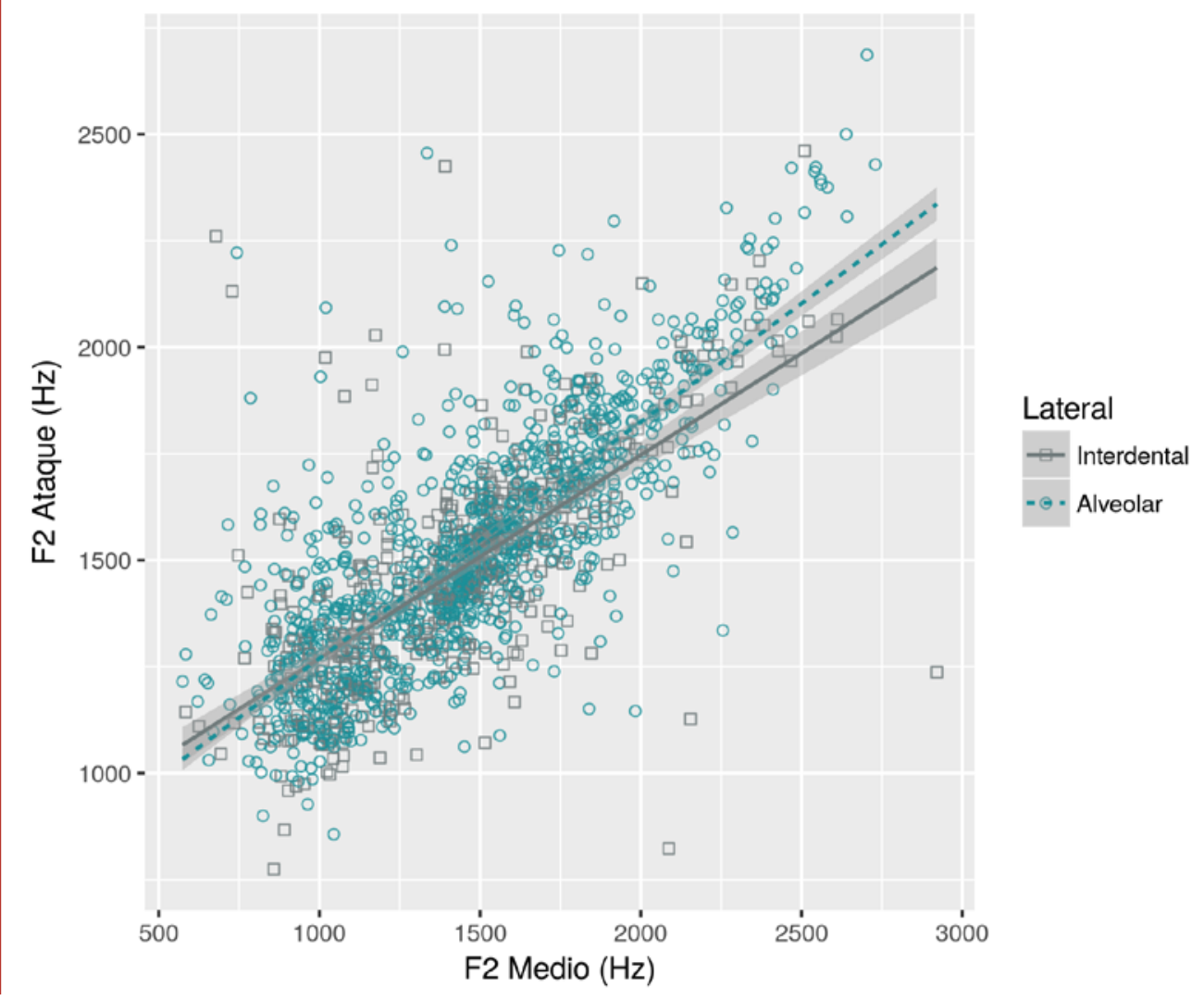

La figura 7 muestra gráficos de caja para los valores de F2 de las consonantes laterales medidos en el ataque en el panel izquierdo y para aquellos medidos al medio de la vocal que sigue a la consonante de interés en el panel derecho, separados por punto de articulación. En el panel izquierdo, para el ataque, se observan valores más bajos de F2 para las consonantes laterales interdentales que para las consonantes laterales alveolares. Estas diferencias, que son relativamente claras en el panel izquierdo, son menos evidentes en el panel derecho, en el que se presentan los datos de F2 medidos en el medio de la vocal que sigue a la consonante. Este hecho es coherente con la asunción de que las diferencias de los valores de F2 debido a la influencia de la consonante deberían disminuir o desaparecer cuando las vocales logran estructuras formánticas estables, y la influencia de la consonante precedente es menos importante. 


\section{FIGURA 7}

Gráfico de cajas para las consonantes laterales que presenta, en el panel izquierdo, los valores de F2 medidos en el ataque y, en el derecho, los valores recogidos al medio de la vocal. En ambos paneles se han separado los valores de las consonantes interdentales $(n=477)$ de aquellos de las alveolares $(n=1054)$
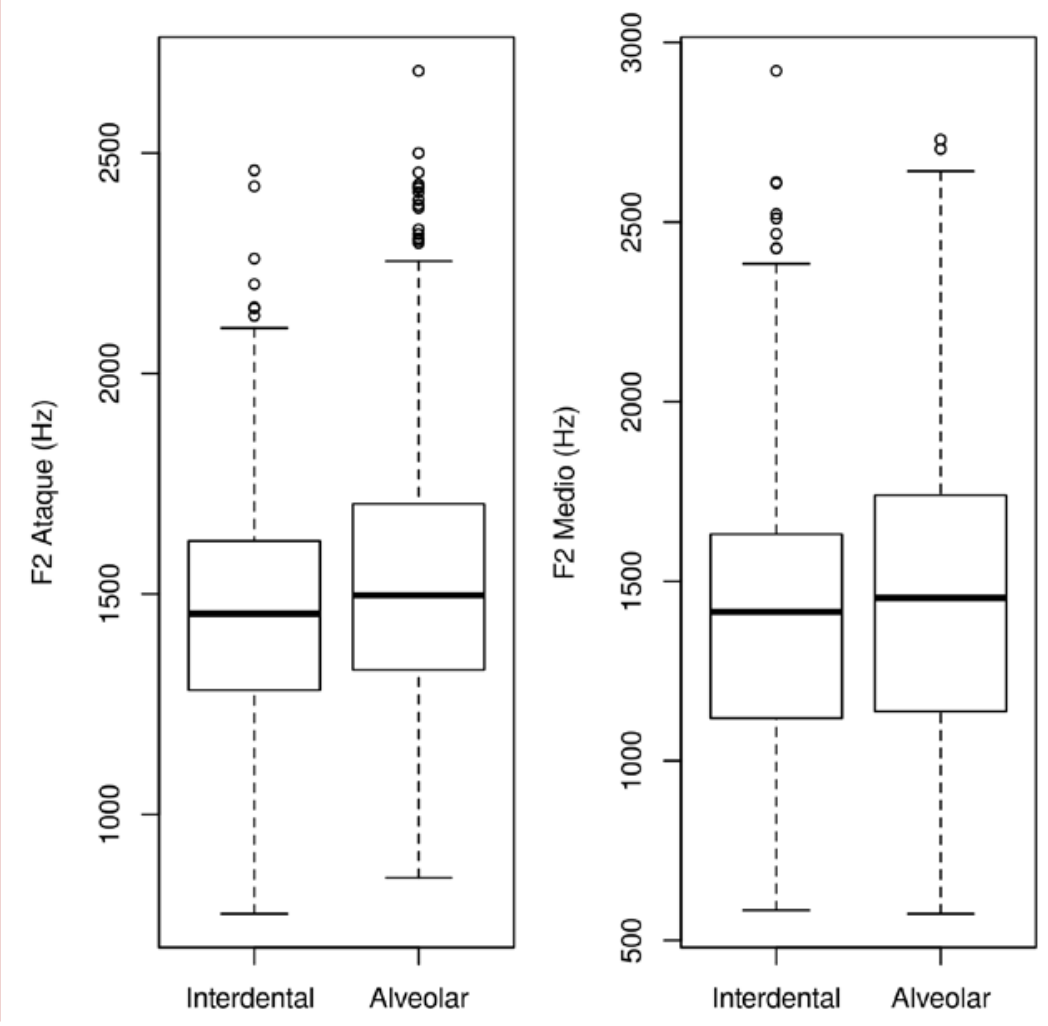

Un análisis de regresión lineal múltiple fue aplicado para evaluar si las variables punto de articulación, vocal y sexo son capaces de predecir los valores de la variable F2 de onset (niveles de referencia para este y los siguientes análisis: consonante lateral interdental, vocal/a/ y sexo femenino). Los resultados indicaron que estas tres variables explican un $65 \%$ de la varianza observada, con significatividad estadística $\left(R^{2}=0.65, \mathrm{~F}(7,1523)=411.3, p<0.001\right)$. Con respecto a la variable punto de articulación, esta fue capaz de predecir la variable dependiente $(\mathrm{B}=$ 2.740, $p<0.01)$, tal que un cambio de consonante lateral interdental a alveolar conduce a un aumento de $28.14 \mathrm{~Hz}$. En el caso de la variable cualidad vocálica, todas la vocales menos /ə/ son capaces de predecir con significatividad estadística las diferencias entre la vocal en cuestión y la vocal /a/ cuando se compara su efecto sobre la variable dependiente. En el caso de/i/, cuando se la compara con /a/, predice un aumento de $570.52 \mathrm{~Hz}(\mathrm{~B}=7.491, p<0.001)$; /e/ predice un aumento de $278.06 \mathrm{~Hz}(\mathrm{~B}=20.354, p<0.001) ; / 0 /$ predice una disminución de $-333.82 \mathrm{~Hz}(\mathrm{~B}=$ $-22.822, p<0.001) ; y / u /$, un descenso de $-339.08 \mathrm{~Hz}(\mathrm{~B}=-23.798, p<0.001)$. Con respecto a la variable sexo, el cambio de hombre a mujer predice un aumento de $227.16 \mathrm{~Hz}$, también con significatividad estadística $(B=21.336, p>0.001)$. Un segundo análisis de regresión lineal múltiple 
evaluó si las mismas variables son capaces de predecir los valores de F2 obtenidos al medio de la vocal, en particular para confirmar la asunción de que las diferencias de F2 correlacionadas con punto articulatorio de la vocal precedente deberían desaparecer una vez que la vocal alcanza valores de F2 estables. El modelo mostró que estas tres variables explican un 75\% de la varianza presente en $\mathrm{F} 2$, con significatividad estadística $\left(R^{2}=0.75, \mathrm{~F}(7,1523)=658, p<0.001\right)$. Nuevamente, todas las vocales - menos/ə/-y la variable sexo fueron capaces de predecir la variable dependiente con significatividad estadística, y en las direcciones teóricamente esperables (aumento de F2 con respecto a /a/ para las vocales anteriores, descenso para las vocales posteriores y aumento de F2 para las mujeres respecto de los hombres). La variable punto de articulación no fue capaz de predecir la variable dependiente ( $B=-0.173, p<0.863$ ).

\subsection{Consonantes nasales}

La figura 8 muestra un gráfico de puntos que dispone en una relación lineal los valores de F2 de consonantes nasales medidos al medio de la vocal, en el eje horizontal, con aquellos obtenidos en el ataque, en el eje vertical. La inspección de la figura 8 revela que para ambos puntos de articulación existe una correlación positiva, tal que, a mayores valores de F2 en la mitad de la vocal, se observan mayores valores de F2 en el ataque. También es posible observar que ambas líneas de regresión lineal ajustadas al gráfico de puntos presentan trayectorias similares, y que los intervalos de confianza que rodean a las líneas de regresión se solapan casi completamente, lo que sugiere que en los datos no existe un correlato acústico de las diferencias acústicas entre las consonantes nasales interdentales y alveolares, al menos cuando las transiciones son modeladas de esta forma.

La figura 9 muestra gráficos de caja para los valores de F2 de las consonantes nasales medidos en el ataque y para aquellos medidos al medio de la vocal que sigue a la consonante de interés, separados por punto de articulación. En ambos paneles no se observan diferencias entre los valores de F2 para el contraste interdental/alveolar, lo que sugiere que las locus equations, y las mediciones de F2 que las integran, no son buenos correlatos de punto articulatorio para el modo de articulación nasal.

Un análisis de regresión lineal múltiple fue utilizado para evaluar si las variables punto de articulación, vocal y sexo son capaces de predecir los valores de la variable F2 en el ataque. Los resultados indicaron que estas tres variables explican un $45 \%$ de la varianza observada en F2, con significatividad estadística $\left(R^{2}=0.44, F(6,760)=103.2, p<0.001\right)$. Con respecto a la variable punto de articulación, esta no fue capaz de predecir la variable dependiente cuando se evalúa el cambio desde una consonante nasal interdental a una alveolar ( $B=1.322, p=0.1866)$. En el caso de la variable cualidad vocálica, todas la vocales evaluadas (no había casos de /i/) fueron capaces de predecir con significatividad estadística las diferencias entre la vocal en 


\section{FIGURA 8}

Gráfico de puntos para los valores de F2 medidos como un promedio al medio de la vocal y para los del ataque, para consonantes nasales interdentales $(n=269)$ y nasales alveolares $(n=498)$. Para cada punto articulatorio se han ajustado líneas de regresión lineal y sus respectivos intervalos de confianza (95\%)

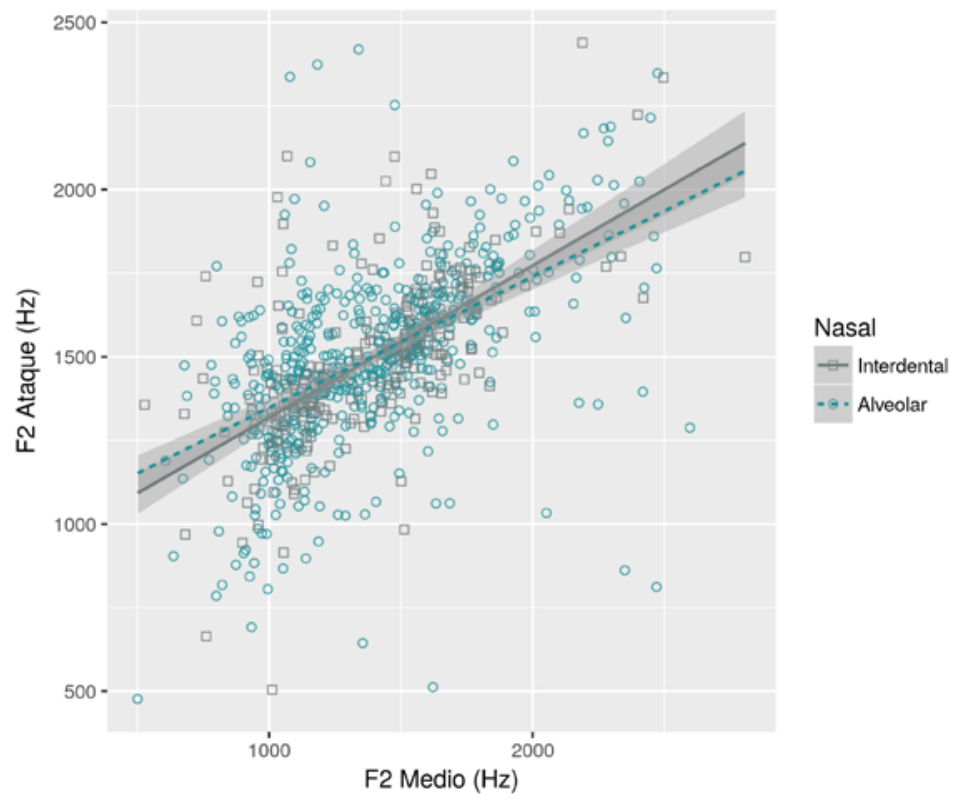

\section{FIGURA 9}

Gráfico de cajas para las consonantes nasales que presenta, en el panel izquierdo, los valores de F2 medidos en el ataque y, en el derecho, los valores recogidos al medio de la vocal. En ambos paneles se han separado los valores de las consonantes interdentales $(n=269)$ de aquellos de las alveolares $(n=498)$
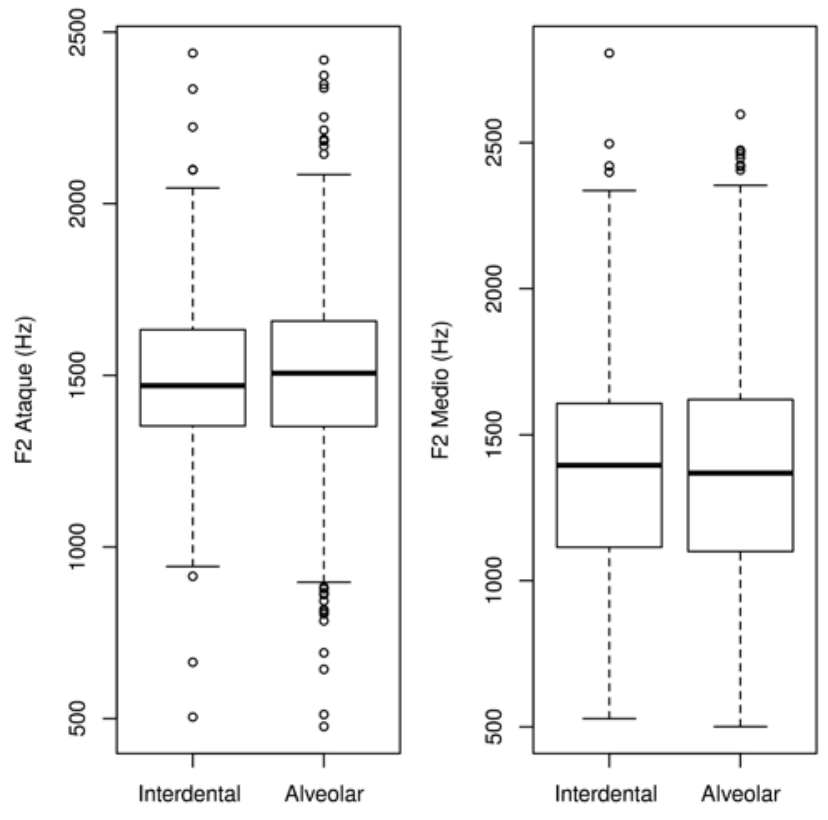
cuestión y la vocal /a/ cuando se compara su efecto sobre la variable dependiente: en el caso de /e/, cuando se la compara con /a/, predice un aumento de 169.05 Hz (B =6.469, $p<0.001)$; la vocal /ə/ predice una disminución de -60.03 Hz ( $\mathrm{B}=-2.416, p<0.05)$; /0/, una disminución de -318.88 Hz ( $B=-13.196, p<0.001) ; y / u /$, un descenso de -294.35 Hz ( $B=-14.613, p<0.001)$. Con respecto a la variable sexo, el cambio de hombre a mujer predice un aumento de $197.57 \mathrm{~Hz}$, con significatividad estadística $(B=11.077, p>0.001)$. Un segundo análisis de regresión lineal múltiple evaluó si las mismas variables son capaces de predecir los valores de F2 obtenidos al medio de la vocal. El modelo utilizado mostró que las variables explican un $70 \%$ de la varianza presente en F2, con significatividad estadística $\left(R^{2}=0.70, F(6,760)=300.2, p<0.001\right)$. Todas las vocales - menos /ə/ - y la variable sexo fueron capaces de predecir la variable dependiente con significatividad estadística, y en las direcciones teóricamente esperadas. La variable punto de articulación no fue capaz de predecir la variable dependiente para las consonantes nasales $(B=-0.189, p<0.850)$.

\subsection{Consonantes oclusivas sordas}

La figura 10 muestra un gráfico de puntos que dispone en una relación lineal los valores de F2 para las consonantes oclusivas sordas obtenidos al medio de la vocal, en el eje horizontal, con aquellos medidos en el ataque, en el eje vertical. La inspección de la figura 10 revela que para ambos puntos de articulación existe una correlación positiva. También es posible observar que ambas líneas de regresión lineal ajustadas al gráfico de puntos presentan trayectorias similares y que sus intervalos de confianza se solapan la mayor parte del tiempo. Sin embargo, a diferencia de lo observado para las consonantes nasales, los puntos para la consonante oclusiva sorda alveolar se concentran en los extremos inferiores de las escalas de F2 (abajo, hacia la izquierda), mientras que los valores de la consonante oclusiva sorda interdental tienden a concentrar sus valores en los rangos medios de las escalas.

La figura 11 muestra gráficos de caja para los valores de F2 de las consonantes oclusivas sordas medidos en el ataque y para aquellos medidos al medio de la vocal, separados por punto de articulación. En el panel izquierdo, se observan valores más altos de F2 para las consonantes oclusivas sordas interdentales que para las consonantes oclusivas sordas alveolares. Estas diferencias, que son relativamente claras en el panel izquierdo, disminuyen en el panel derecho, dado que las dos distribuciones presentan mayor solapamiento.

Un análisis de regresión lineal múltiple evaluó si las variables punto de articulación, vocal y sexo son capaces de predecir los valores de F2 de las consonantes oclusivas sordas obtenidos en el ataque. Los resultados mostraron que estas tres variables, en su conjunto, explican un $67 \%$ de la varianza observada en $\mathrm{F} 2$, con significatividad estadística $\left(R^{2}=0.67, \mathrm{~F}(6,1132)=\right.$ $389, p<0.001$ ). Con respecto a la variable punto de articulación, esta fue capaz de predecir la 


\section{FIGURA 10}

Gráfico de puntos para los valores de F2 medidos como un promedio al medio de la vocal y para los del ataque, para consonantes oclusivas sordas interdentales $(n=615)$ y oclusivas sordas alveolares $(n=524)$. Para cada punto articulatorio, se han ajustado líneas de regresión lineal y sus respectivos intervalos de confianza (95\%)

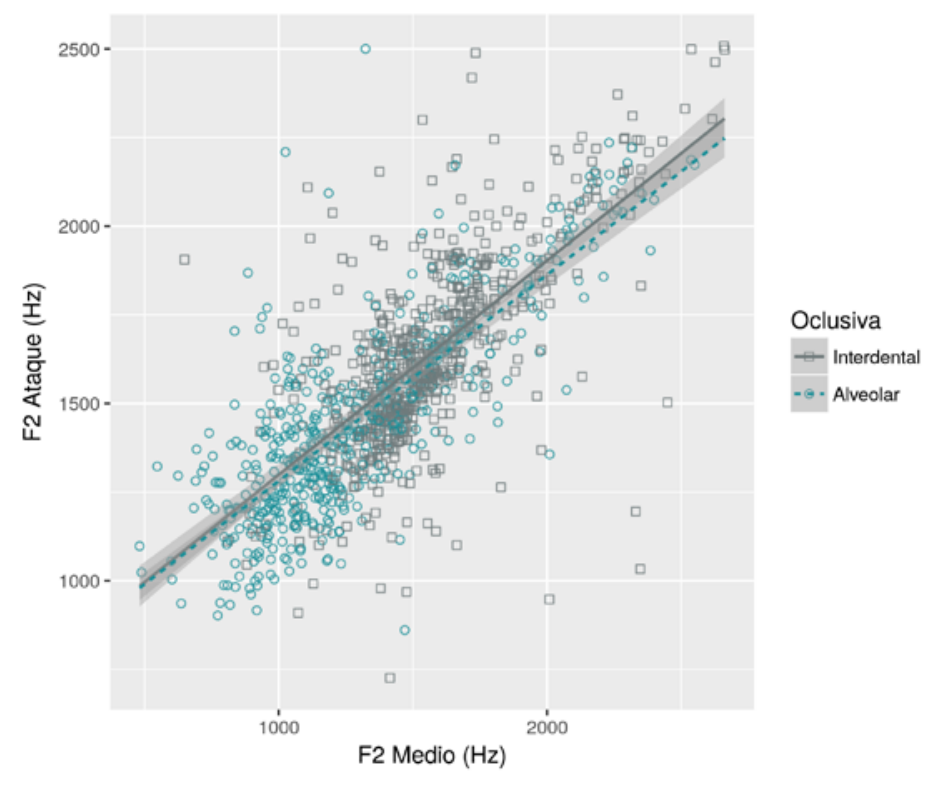

\section{FIGURA 11}

Gráfico de cajas para las consonantes oclusivas sordas que presenta, en el panel izquierdo, los valores de F2 medidos en el ataque y, en el derecho, los valores recogidos al medio de la vocal. En ambos paneles se han separado los datos de las consonantes interdentales $(n=615)$ de aquellos de las alveolares $(n=524)$
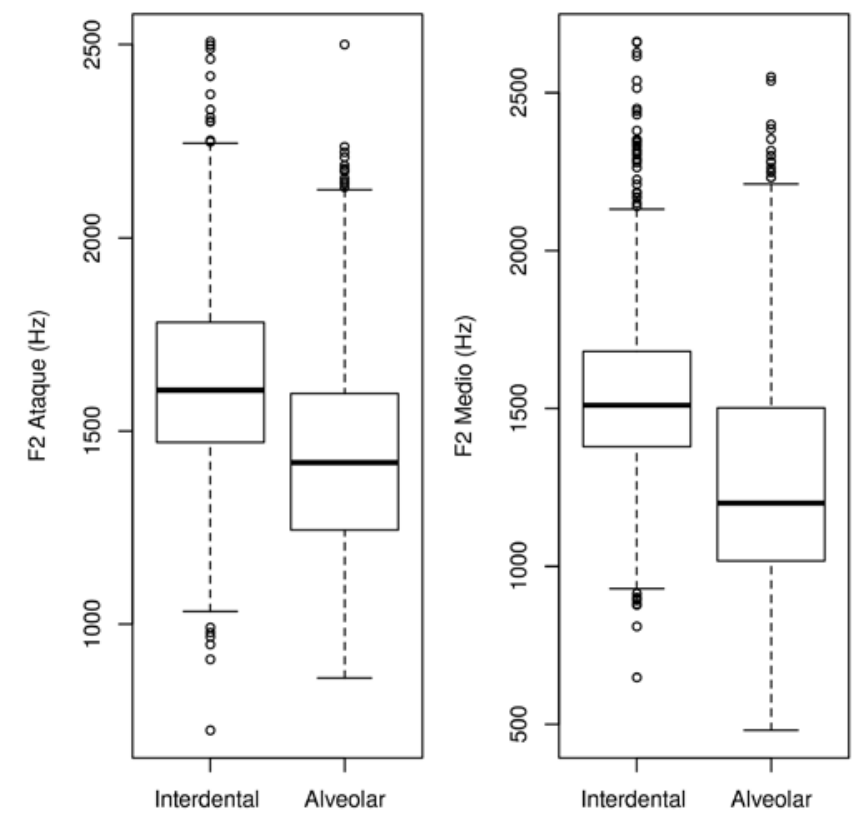
variable dependiente cuando se compara el efecto en F2 del cambio entre una oclusiva sorda interdental a una alveolar ( $\mathrm{B}=-3.357, p<0.001)$; en particular, el modelo predice una disminución de $-46.582 \mathrm{~Hz}$. En el caso de la variable cualidad vocálica, todas la vocales evaluadas (no había casos de /o/) fueron capaces de predecir con significatividad estadística las diferencias entre la vocal en cuestión y la vocal /a/: /e/ predice un aumento de $320.73 \mathrm{~Hz}(\mathrm{~B}=12.730, p<$ $0.001) ; /$ / / predice un aumento de $63.36 \mathrm{~Hz}(\mathrm{~B}=4.007, p<0.001)$; /i/ predice un aumento de 521.26 $\mathrm{Hz}(\mathrm{B}=21.692, p<0.001) ; \mathrm{y} / \mathrm{u} /$, un descenso de $-317.75 \mathrm{~Hz}(\mathrm{~B}=-20.167, p<0.001)$. Con respecto a la variable sexo, el cambio de hombre a mujer predice un aumento de $261.571 \mathrm{~Hz}$, con significatividad estadística $(B=20.821, p>0.001)$. Un segundo análisis fue aplicado para evaluar si las mismas variables eran capaces de predecir los valores de F2 obtenidos en la mitad de la vocal. El modelo mostró que las variables explican un $72 \%$ de la varianza presente en $\mathrm{F} 2$, con significatividad estadística $\left(R^{2}=0.7183, F(6,1132)=484.7, p<0.001\right)$. Todas las vocales evaluadas y la variable sexo fueron capaces de predecir la variable dependiente con significatividad estadística y en las direcciones teóricamente esperadas. La variable punto de articulación, sin embargo, no fue capaz de predecir la variable dependiente $(B=-1.558, p=0.12$ ).

\subsection{Síntesis de resultados}

Los resultados observados en las secciones anteriores muestran que, para las consonantes laterales y oclusivas sordas, las diferencias entre los puntos articulatorios interdental y alveolar son capaces de predecir diferencias en la variable dependiente, con significatividad estadística. Este no fue el caso para el contraste interdental/alveolar de las consonantes nasales. En el caso de los valores obtenidos como promedio en el sector central de la vocal, ningún contraste de punto articulatorio fue capaz de predecir un efecto sobre el F2. Como era de esperar, en general, las vocales resultaron ser buenas predictoras de los valores formánticos de F2, tanto en el ataque como en la mitad de la vocal, y en las direcciones esperables. Solo la vocal/ə/ constituye una excepción a este esquema general. En todos Ios análisis, la variable sexo resultó ser una buena predictora de los valores de F2.

\section{Discusión}

Como se mencionó anteriormente, existe una tendencia entre las investigaciones respecto del contraste interdental/alveolar de asignar o no estatus fonémico a la serie completa de interdentales, sin hacer distinción entre unas u otras, especialmente en aquellos trabajos en los que solo se apela al método distribucional. Así, por ejemplo, Suárez (1959), Echeverría (1964), Salas (1976, 1978), Lagos (1981), Salamanca (1997), entre otros, asignan estatus fonémico a la serie completa de interdentales, mientras que Croese (1980), Smeets (1989), Salamanca y Quintrileo (2009), entre otros, consideran los tres segmentos como alófonos de las alveolares 
correspondientes, sin hacer, tampoco, diferencias entre ellas. Cuando se han contabilizado frecuencias de aparición de variantes, se sigue una tendencia similar, a pesar de que puede haber diferencias importantes en el porcentaje de ocurrencias entre una variable y otra. Es el caso, por ejemplo, del estudio de Pérez y Salamanca (2017), en el que el fonema lateral interdental presenta un mayor porcentaje de realizaciones alveolares (67\%) y, sin embargo, recibe estatus fonémico, al igual que los segmentos oclusivo y nasal, en los que el porcentaje de realizaciones interdentales supera siempre el 50\%. Se trata en ese caso de una decisión compatible con el principio de tendencia a la simetría de los sistemas fonético-fonológicos, pero que, sin duda, es discutible. En este sentido, parece relevante problematizar la premisa utilizada sistemáticamente en la literatura fonético-fonológica del mapudungun, en cuanto a la tendencia a la simetría de los sistemas fonético-fonológicos; especialmente, cuando se trata de lenguas en contacto, en situación de minorización o desplazamiento. Un acercamiento como el realizado en este estudio pareciera avenirse de mejor manera con los matices y desfases asociados a las situaciones particulares del contacto, circunstancias en las que los comportamientos regulares y estables no son siempre la norma.

Por otro lado, en uno de los escasos estudios que incluye una frecuencia de fonemas del mapudungun, como es el de Lagos (1981), el fonema nasal interdental se presenta con el menor porcentaje de frecuencia de todos los fonemas, con un $0.15 \%$. Es probable que esta escasa frecuencia haga más vulnerable a la desfonologización a dicho segmento. Lo es así, por lo menos, para la zona estudiada.

Desde una perspectiva metodológica, las técnicas utilizadas demuestran ser capaces de recoger información relevante sobre diferencias de punto articulatorio de consonantes interdentales y alveolares, lo que releva la importancia de la incorporación de metodologías de la fonetica acústica y estadística inferencial para avanzar en el conocimiento de asuntos relacionados con problemas fonológicos y procesos de cambio lingüístico de las lenguas vernáculas. Resultados como los que se reportan en este trabajo, elaborados con muestras de gran tamaño, contribuyen a enriquecer el estado del arte con matices que resultan difíciles de observar mediante metodologías tradicionales.

Aunque en este estudio las locus equations hayan provisto resultados coherentes con las observaciones realizadas sobre la naturaleza acústica de los datos, su utilización no se encuentra exenta de críticas, y por varias razones (Fowler, 1994). No se realizará aquí una discusión sobre sus ventajas y desventajas, pero sí es importante reparar en el rol que los procesos de normalización de valores formánticos pueden tener en los resultados. Como se anticipó en las secciones destinadas a la metodología, en ningún estudio del que se tenga noticia se han implementado métodos de normalización de formantes vocálicos antes de analizar los valores de F2 en el contexto de locus equations. Este hecho puede obedecer tanto a razones relacionadas con el tipo de muestra utilizada — por ejemplo, Fasola y otros (2015) reportan da- 
tos de un solo participante, por lo que no es necesario normalizar los valores de F2- o con el método propiamente tal, que descansa en diferencias de $\mathrm{F} 2$ relativamente pequeñas. De hecho, Ios análisis de regresión lineal múltiple mostraron que, en aquellos modos de articulación en los que sí se observó un efecto del punto de articulación en los valores de F2 del ataque, la diferencia de F2 predicha por el modelo oscila en un rango entre $28 \mathrm{~Hz}$ y $47 \mathrm{~Hz}$ (para las consonantes laterales y oclusivas sordas, respectivamente), valores que, en el contexto del rango de variación normal de F2, pueden ser considerados como relativamente pequeños (HiIlenbrand, Getty, Clark y Wheeler, 1995). Dado que no se normalizaron los datos, no es posible descartar que los efectos observados para el contraste interdental/alveolar en laterales y alveolares se deban, quizás en parte, a diferencias anatómicas entre hombres y mujeres; de hecho, la variable sexo presentó un efecto significativo en los valores de F2 en todos los análisis.

Otro asunto que merece atención es la ausencia de un efecto de la variable punto de articulación en los resultados de F2 para el ataque de las consonantes nasales. Mientras la ausencia de un efecto puede deberse, efectivamente, a la ausencia de diferencias en los valores de F2 debido a la ausencia de un correlato acústico y tal vez articulatorio (como lo sugieren las figuras 8 y 9), también es posible que la nasalización de las vocales contiguas esté oscureciendo los datos. De hecho, la nasalización de vocales añade picos espectrales entre los primeros formantes (Chen, 1997), de manera que la estimación de formantes vocálicos para las vocales nasalizadas puede no ser tan exacto como para las laterales y oclusivas sordas. Tanto este asunto como el rol de las normalizaciones de formantes vocálicos en el cálculo de locus equations deberán ser explorados en futuras incursiones sobre este tema.

\section{Conclusiones}

La evidencia acústica y estadística recogida en las secciones anteriores da sustento a las hipótesis de contraste entre las variantes interdentales y alveolares de las consonantes laterales y oclusivas sordas, pero no para las consonantes nasales. También se observó un claro efecto de la cualidad vocálica en los valores de F2, incluso para aquellos recogidos en el ataque. Parece evidente que el impacto del sistema fonético-fonológico del español en la zona no ha sido irrelevante, pues ha implicado la pérdida de un segmento fónico funcional: la consonante nasal interdental. Esto es aún más sensible si se considera que el promedio de edad de los colaboradores es de 64 años, edad en que los estudios de vitalidad han señalado tiende a haber un mantenimiento importante de la lengua (Gundermann y otros, 2009). En este sentido, la zona estudiada podría situarse en un lugar intermedio entre la alta vitalidad del vernáculo en la población adulta de Alto Bío Bío y el desmantelamiento del sistema fonético-fonológico del huilliche osornino. En efecto, el estudio de Mena (2016) da cuenta de que el porcentaje de realizaciones indicadoras de vitalidad en la población adulta de Alto Bio Bío es de un 83\%, mientras que el estudio clásico de Álvarez-Santullano (1986) informa de un 
número importante de desfonologizacones y fluctuaciones de fonemas asociados a la inestabilidad del sistema fónico vernacular.

\section{Bibliografía citada}

Adank, Patti, Roel Smits y Roeland van Hout, 2004: "A comparison of vowel normalization procedures for language variation research", The Journal of the Acoustical Society of America 116 (5), 3099-3107.

Álvarez-Santullano, Pilar, 1986: Descripción fonológica del huilliche, un dialecto del maúche araucano del centro-sur de Chile. Tesis de maestría, Universidad de Concepción, Chile.

Anderson, Victoria, 2008: "Static Palatography for Language Fieldwork", Language Documentation \& Conservation 2 (1), 1-27.

Boersma, Paul, y David Weenink, 2016: Praat: doing phonetics by computer, programa computacional [obtenido de http://www.praat.org/].

Chen, Marilyn, 1997: "Acoustic correlates of English and French nasalized vowels", The Journal of the Acoustical Society of America 102 (4), 2360-2370.

Croese, Robert, 1980: “Estudio dialectológico del mapuche”, Estudios Filológicos 15, 7-38.

CRoISSANT, Yves, 2013: mlogit: multinomial logit model, programa computacional. R package version 0.2-4 [obtenido de http://CRAN.R-project.org/package=mlogit].

Echeverría, Max, 1964: "Descripción fonológica del mapuche actual”, Boletín del Instituto de Filología de la Universidad de Chile XVI, 13-59.

Fasola, A. Carlos, Héctor Painequeo Paillan, Seunghun J. Lee y Jeremy Perkins, 2015: "Acoustic properties of the dental vs. alveolar contrast in Mapudungun", Proceedings of the I8th International Congress on Phoneic Sciences.

Fowler, Carol A., 1994: "Invariants, specifiers, cues: An investigation of locus equations as information for place of articulation”, Perception \& Psychophysics 55 (6), 597-610.

Fuentes-Grandón, Darío, y Gastón Salamanca Gutiérrez, 2016: “¿Los fonemas /v/ y /ð/ presentan alófonos aproximantes en el Chedungun hablado en el Alto Bío-bío?: Evidencias desde una perspectiva acústica”, Literatura y Lingüística 33, 267-288.

Gundermann, Hans, Jaqueline Canihuan, Alejandro Clavería y César Faúndez, 2009: "Permanencia y desplazamiento, hipótesis acerca de la vitalidad del mapuzugun”, Revista de lingüística teórica y aplicada 47 (1), 37-60. 
Henríuez, Marisol, y Gastón Salamanca, 2015: "Vitalidad de la fonología segmental del chedungun hablado por escolares del Alto BioBío”, Alpha 41, 207-231.

Henriquez, Marisol, 2013: Vitalidad fonológica del mapudungun en escolares mapuches pewenches y lafkenches de la VIII región del Biobío. Tesis doctoral, Universidad de Concepción, Chile.

Hillenbrand, James, Laura A. Getty, Michael J. Clark y Kimberlee Wheeler, 1995: "Acoustic characteristics of American English vowels", The Journal of the Acoustical society of America 97 (5), 3099-3111.

Iskarous, Khalil, Carola A. Fowler y Douglas H. Whalen, 2010: "Locus equations are an acoustic expression of articulator synergy", The Journal of the Acoustical Society of America 128 (4), $2021-2032$.

Lagos, Daniel, 1981: “El estrato fónico del mapudungu(n)”, Nueva Revista del Pacífico 19-20, 42-66.

LAmBert, Wallace E., 1955: "Measurement of the linguistic dominance of bilinguals", The journal of abnormal and social psychology 50 (2), 197.

Liberman, Alvin M., Franklin S. Cooper, Donald P. Shankweiler y Michael Studdert-Kennedy, 1967: “Perception of the speech code", Psychological review 74 (6), 431.

Liberman, Alvin M., Pierre Delattre y Franklin S. Cooper, 1952: "The role of selected stimulus-variables in the perception of the unvoiced stop consonants", The American journal of psychology $65(4), 497-516$.

Liberman, Alvin M., Pierre Delattre, Franklin S. Cooper y Louis J. Gerstman, 1954: "The role of consonant-vowel transitions in the perception of the stop and nasal consonants", Psychological Monographs: General and Applied 68 (8), 1.

Lobanov, Boris Mefodevich, 1971: "Classification of Russian vowels spoken by different listeners", Journal of the Acoustical Society of America 49, 606-08.

Mena, Daniela, 2016: Transferencias del español y estatus fonético-fonológico de [J] en el chedungun hablado en Alto Bío-Bío. Tesis de maestría, Universidad de Concepción, Chile.

Nearey, Terence M., 1977: Phonetic Feature Systems for Vowels. Tesis doctoral, University of Alberta, Edmonton, Alberta, Canada.

Painequeo, J. Héctor, 2014: El estatus fonológico de los segmentos (inter)dentales de [t], [l], [n], y el fono alveopalatal fricativo [J] en el sistema fonológico de la lengua mapuche del sector Budi, de la Región de La Araucanía, Chile. Tesis doctoral, Universidad de Concepción, Chile.

Pérez, Chery, y Gastón Salamanca, 2017: "El mapuche hablado en Curarrehue: Fonemas segmentales, fonotaxis y comparación con otras variedades”, Literatura y Lingüística 35, 315-336. 
PIKE, Kenneth, 1971 [1947]: Phonemics. A technique for Reducing Languages to writing, Michigan: The University of Michigan Press.

Pisanski, Katarzyna, Paul J. Fraccaro, Cara C. Tigue, Jillian J. M. O’Connor, Susanne Röder, Paul W. AnDRews, Bernhard Fink, Lisa DeBruine, Benedict C. Jones y David R. FeinberG, 2014: "Vocal indicators of body size in men and women: a meta-analysis", Animal Behaviour 95, 89-99.

R CORE TEAm, 2017: R: A language and environment for statistical computing, programa computacional [obtenido de https://www.R-project.org/].

Sadowsky, Scott, Héctor Painequeo, Gastón Salamanca y Heriberto Avelino, 2013: "Mapudungun", Journal of the International Phonetic Association 43 (1), 87-96.

Salamanca, Gastón, y Elizabeth Quintrileo, 2009: “El mapuche hablado en Tirúa: fonemas segmentales, fonotaxis y comparación con otras variedades", Revista de Lingüística Teórica y Aplicada 47, 13-35.

Salamanca, Gastón, 1997: “Fonología del pehuenche hablado en Alto Bío-Bío”, Revista de Lingüística Teórica y Aplicada 35, 113-124.

Salamanca, Gastón, Jaime Soto, Héctor Painequeo y Manuel Jiménez, 2017: "Reanálisis de aspectos controversiales de la fonología del chedungun hablado en Alto Bío-Bío: el estatus fonéticofonológico de las interdentales [t] ] [n] y [1]", Alpha, 45, 273-289.

SALAS, Adalberto, 1976: "Esbozo fonológico del mapudungu, lengua de los mapuches o araucanos de Chile central”, Estudios Filológicos 11, 143-153.

SALAS, Adalberto, 1978: “Mapuche-Español. Análisis fonológico contrastivo”, Cuadernos de Lingüística 2, 57-85.

SALAS, Adalberto, 2006 [1992]: El mapuche o araucano, Madrid: Mapfre.

SmeEts, Ineke, 1989: A mapuche Grammar. Tesis doctoral, Rijksuniversiteit te Leiden, Alemania.

Soto-Barba, Jaime, Isolina LaRa y Gastón Salamanca, 2016: "Descripción fonético-acústica de la sexta vocal en el chedungun hablado en Alto Bío-Bío”, Onomázein 34, 229-241.

SUÁREZ, Jorge A., 1959: "The phonemes of an Araucanian dialect", International Journal of American Linguistics 25 (3), 177-181.

Sussman, Harvey M., Helen A. McCaffrey y Sandra A. Matthews, 1991: "An investigation of locus equations as a source of relational invariance for stop place categorization", The Journal of the Acoustical Society of America 90 (3), 1309-1325. 
Sussman, Harvey M., Kathryn A. Hoemeke y Farhan S. Ahmed, 1993: "A cross-linguistic investigation of locus equations as a phonetic descriptor for place of articulation", The Journal of the Acoustical Society of America 94 (3), 1256-1268.

WitTIG, Fernando, 2009: "Desplazamiento y vigencia del mapudungún en Chile: un análisis desde el discurso reflexivo de los hablantes urbanos", Revista de Lingüística Teórica y Aplicada $47,135-155$.

ZúñIGA, Fernando, 2007: "Mapuduguwelaymi am ¿acaso ya no hablas mapudungun? Acerca del estado actual de la lengua mapuche”, Estudios Públicos 105, 9-24. 